\title{
Viviendas construidas con un sistema especial
}

\author{
M. Abad, L. Sảnchez Lozano y E. Montero*
}

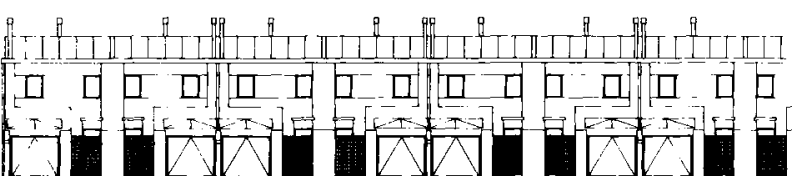

Alzado anterior

\section{EL PROYECTO}

El presente proyecto de 32 viviendas forma parte de una actuación emprendida por la Dirección General de Arquitectura de la Comunidad Autónoma de Madrid en 1985. Dentro de esta experiencia, el proyecto buscaba la realización de viviendas de bajo coste de construcción.

Basándose en esta idea, se inició una búsqueda de materiales y sistemas constructivos que supusieran un ahorro económico evidente de la obra. Ahorro tanto en el coste de los materiales como en su ejecución, y que la repercusión de la mano de obra (de gran fluctuación y rendimientos poco claros), fuera escasa.

El sistema constructivo empleado en el proyecto está constituido por un panel compuesto por un alma de poliestireno expandido de $7 \mathrm{~cm}$ de espesor y dos mallazos unidos mediante conectores de acero. El montaje se realiza a mano, uniendo los paneles entre sí y a la estructura por medio de solapes de mallazo y varilla de acero. Una vez montado este "esqueleto aislante" se proyecta una capa de microhormigón de 3 a $5 \mathrm{~cm}$ de espesor por cada cara. El muro así conseguido es portante, habiendo resistido en ensayos previos cargas de hasta $40 \mathrm{t} / \mathrm{ml}$.

Los costes del panel, la rapidez de ejecución y el cumplimiento de toda la normativa de V.P.O. hacían idóneo su uso en la elaboración del proyecto. Por otra parte, las características portantes del panel, de cerramiento y de ejecución, se adaptaban muy bien a la tipología de vivienda en hilera.

"Goya, 46, $2 .^{\circ}$

28001 Madrid/España

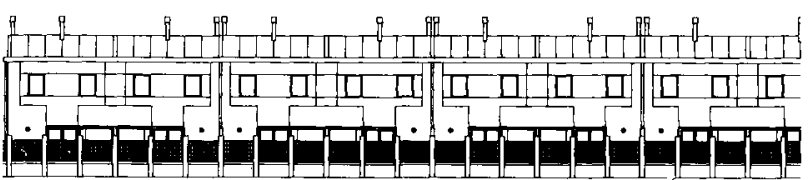

Alzado posterior

La experiencia del sistema era escasa, por lo que detalles resueltos en la práctica constructiva tradicional se convertian en un problema más, con los que encuentros con carpinterías, juntas de dilatación, etc., asi como su aplicación a elementos estructurales como vigas, losas, etc., eran detalles a investigar.

Aunque es más que deseable un rigor modular, el sistema permite una gran flexibilidad compositiva, tanto en la disposición de huecos como en su dimensión. De todas maneras, $s \in$ ha realizado un proyecto para este tipo de tecnología y no al revés, siendo la tipología de vivienda, como se indicó anteriormente, muy apropiada para la aplicación del sistema.

Los muros medianeros de carga, fachada y cubierta se realizan con los paneles. El forjado de planta baja descansa sobre una fábrica de bloques de hormigón, aprovechando el zuncho perimetral para realizar las esperas de los paneles que sirven como guías de éstos; de este modo se consigue una perfecta continuidad entre el muro portante y la cimentación.

El forjado de planta primera se resuelve de forma tradicional (vigueta semirresistente y bovedilla cerámica), introduciéndose en el eje de la vivienda un panel para realizar el hueco de la escalera, dejando un vano de la mitad de la luz entre muros medianeros; el paso hacia el cuarto de baño se realiza mediante una pasarela muy ligera realizada con perfiles tipo IPE y chapa metálica.

La escalera se coloca en el hueco resultante y se convierte en el elemento organizador de la vivienda.

La cubierta se realiza con una losa de hormigón; para ello se utiliza el panel base como encofrado perdido, 


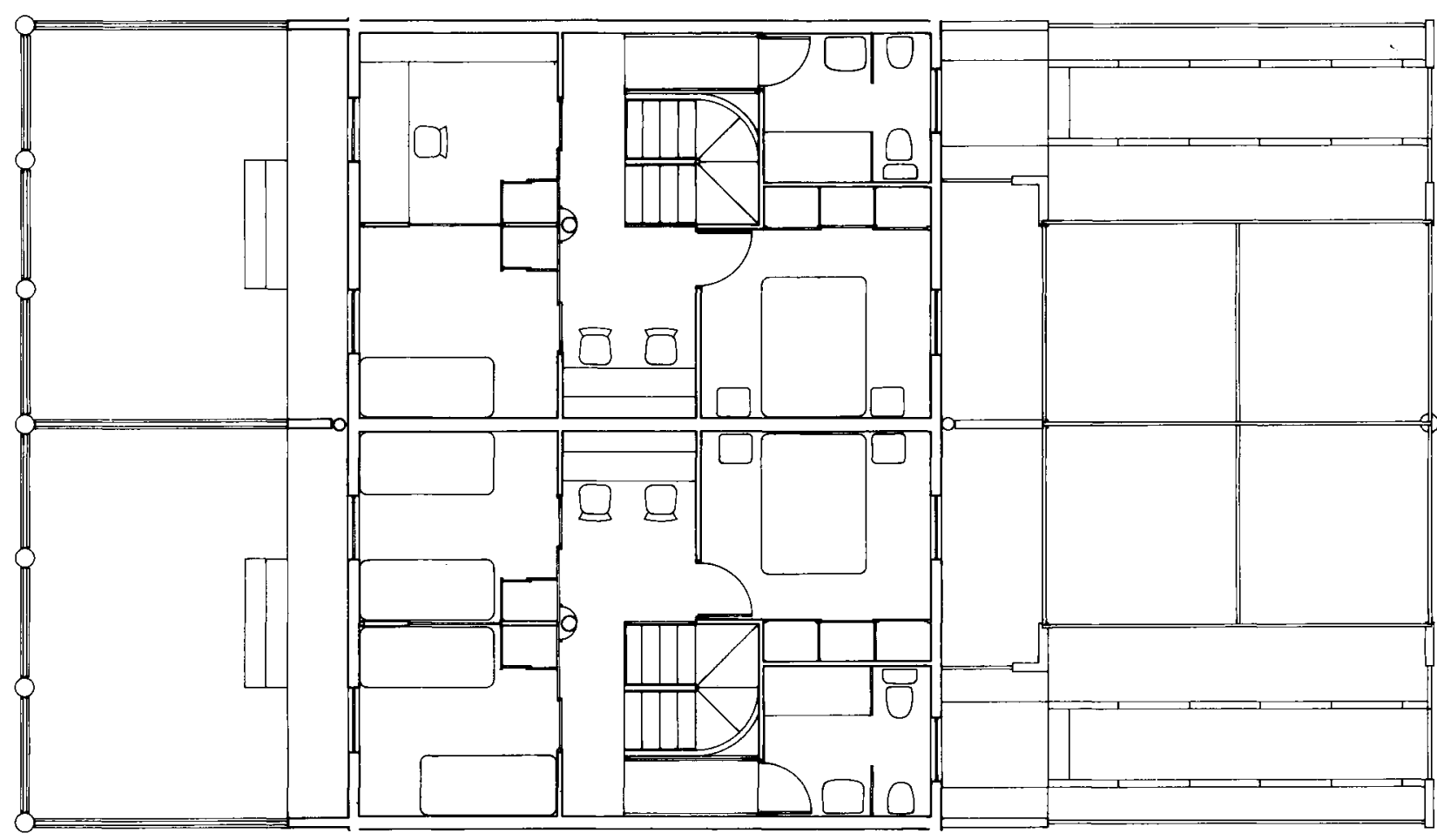

Planta alta

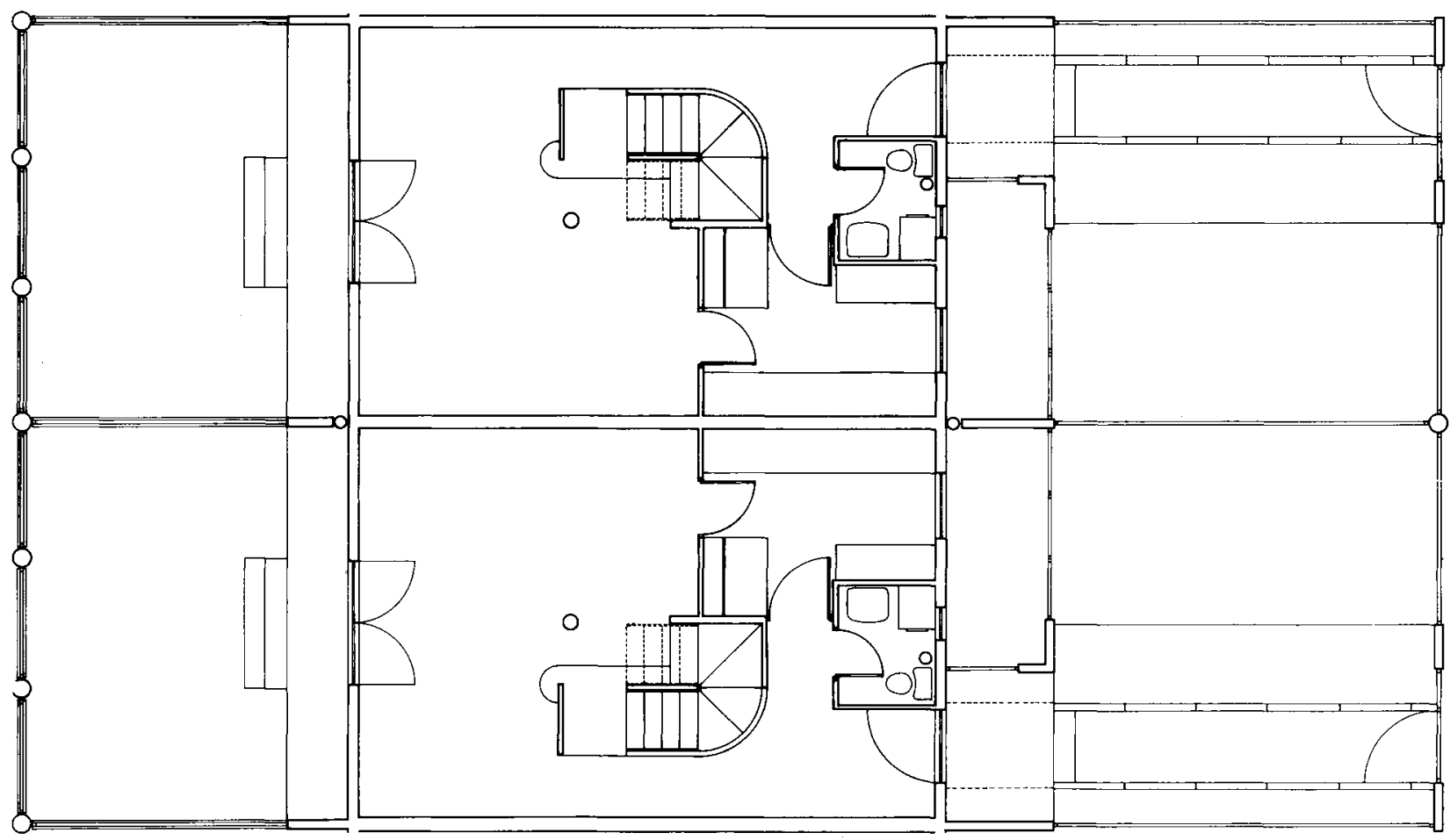



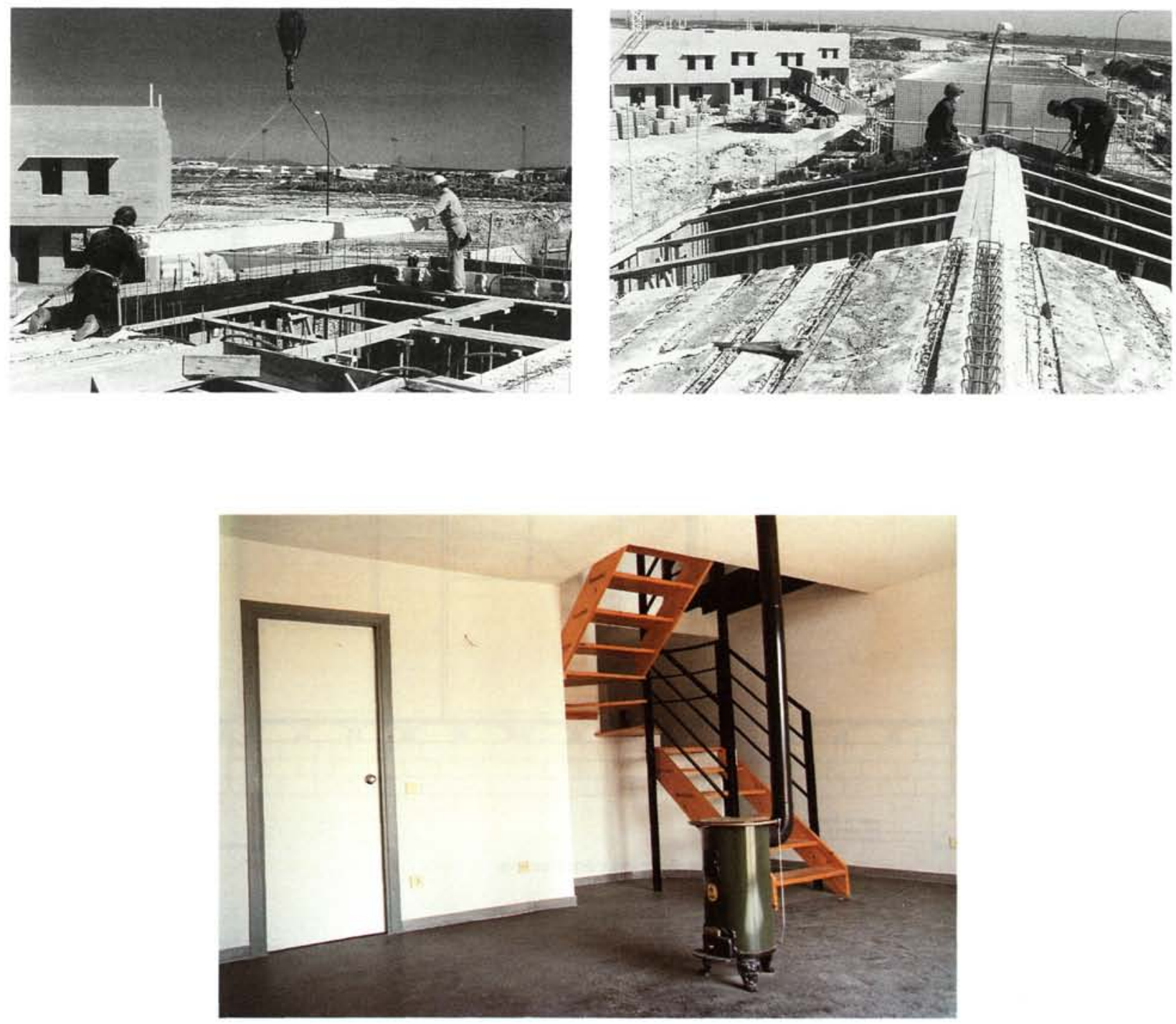

la losa apoya en los paneles de fachada y en dos grandes vigas de canto que, a la vez que atan todos los muros medianeros, conforman un pequeño espacio iluminado cenitalmente alrededor de los dormitorios.

El mismo sistema de losa se utiliza para realizar una pequeña marquesina en el acceso a la vivienda ya que, en principio, no planteaba serios problemas el proyectado horizontal del microhormigón.

La cobertura se ejecuta con placas de fibrocemento, rematando a modo de alero un gran canalón de chapa galvanizada. Las bajantes, exteriores, suavizan la dureza de los alzados.
En el interior de las viviendas, la elección de los materiales sigue la idea general del proyecto, coste competitivo, rapidez de ejecución, etc., destacando como elementos más significativos la tabiquería con paneles de cartón-yeso y el solado con baldosas de amianto-vinilo. A los paramentos verticales formados por los paneles, se les aplicaba un pequeño enlucido, con el fin de homogeneizar la planeidad de los mismos.

En el exterior se continúa utilizando los paneles para la realización de los cerramientos; éstos sirven de soporte a todos los elementos de cerrajería, aunque en la zona posterior se utilizan tubos de fibrocemento de alta presión rellenos de hormigón. 


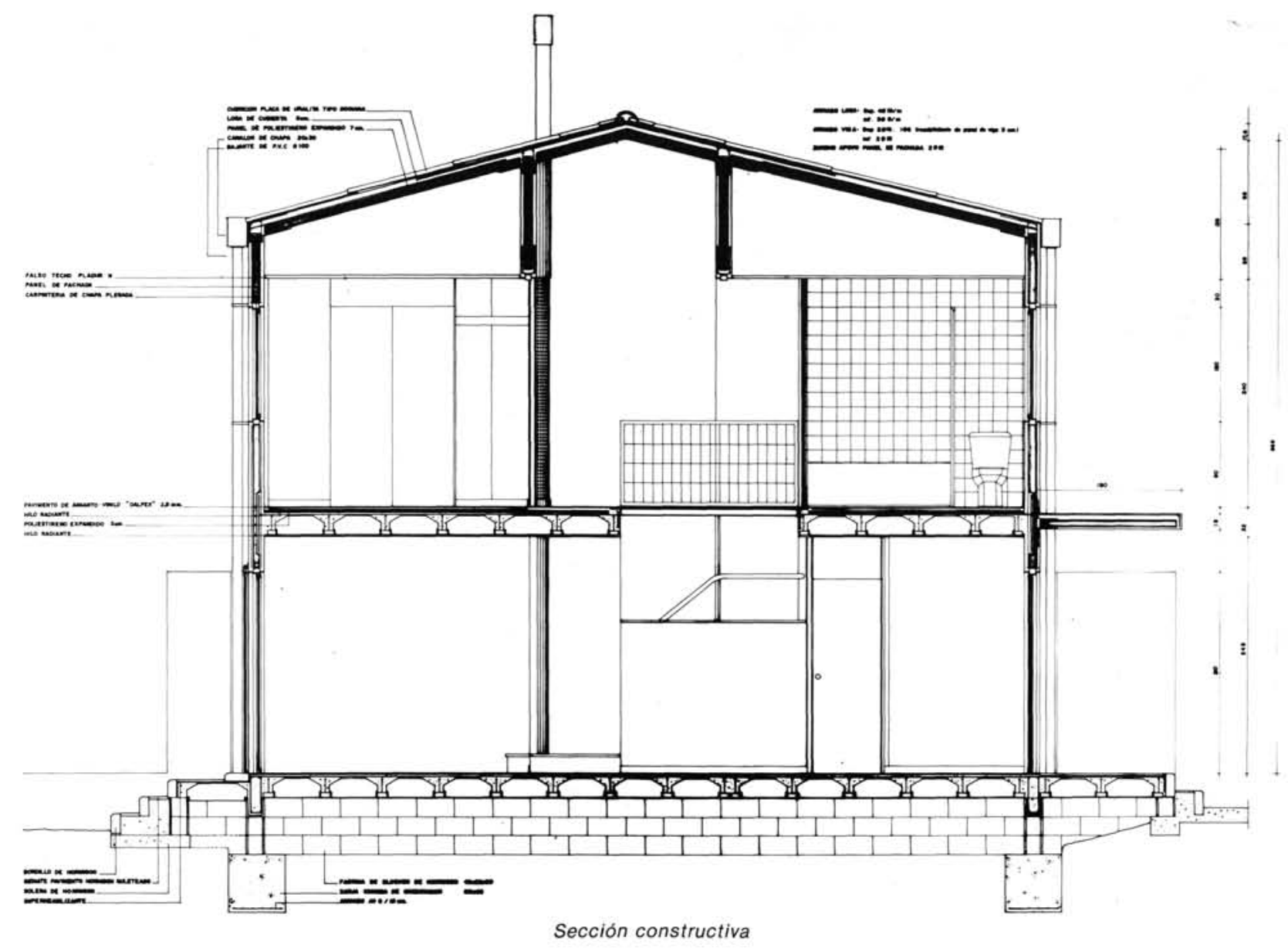

Las instalaciones eléctricas se alojan en el interior de los paneles; para ello durante la colocación de éstos se abren las correspondientes "rozas" en el poliestireno con aire caliente. Es un proceso que aunque requiere un cuidadoso replanteo se solapa perfectamente y sin interferencia con el proceso general de montaje.

De todas maneras, en la elaboración del proyecto, se hizo el esfuerzo de dibujar todos los trazados de éstas, huyendo de los habituales esquemas.

Las instalaciones de fontaneria se pueden realizar de la misma forma, siempre y cuando las zonas no afecten a muros estructurales en cuyo caso, y en previsión de reposiciones y mantenimiento, se alojan en tabiques técnicos.

\section{LA OBRA}

Se adjudicó la realización de las obras a Dragados y Construcciones, ya que esta empresa habia desarrollado una gran investigación sobre este sistema constructivo, y habia obtenido el Documento de Idoneidad Técnica concedido por el Instituto Eduardo Torroja de acuerdo a las directrices de la "Union Européenne pour l'Agrement Tecnique dans la Construction"; además habia realizado con éxito diversas construcciones con una variedad del sistema para edificios en altura (EI Dragados Plastbau II) aunque nunca habia dispuesto de un proyecto concebido para esta tecnologia; en cualquier caso sí que existia una amplia investigación en la resolución de detalles de encuentros. De todas ma. neras, las investigaciones y la consecución del Documento de Idoneidad Técnica por parte de la empresa constructora eran una garantía para el buen fin de las obras. 


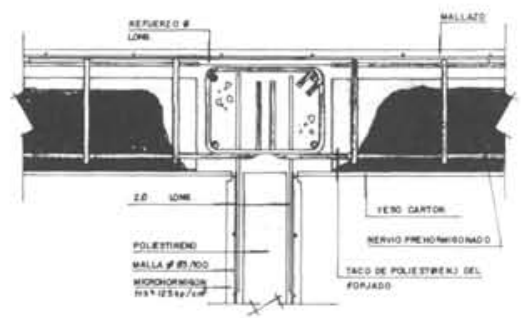

Detalle, unión de forjado de cubierta con muro intermedio.

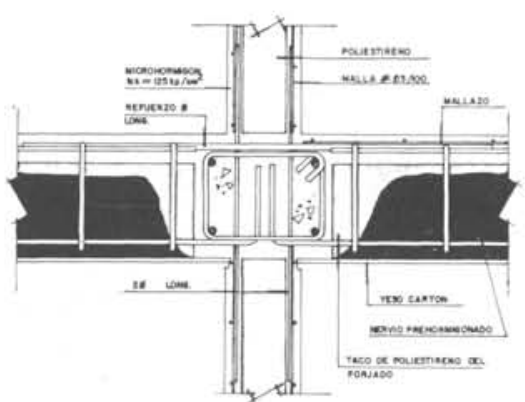

Detalle, unión de

forjado con muro intermedio.

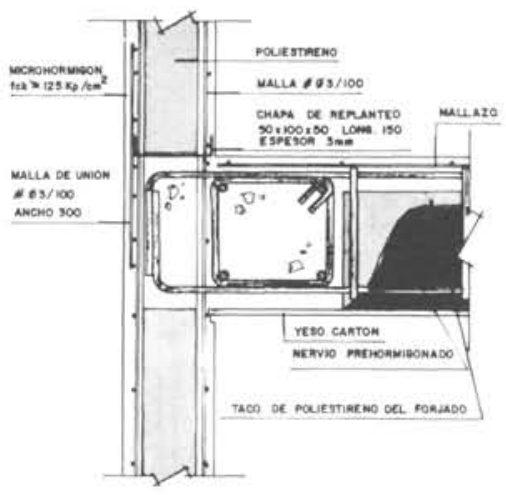

Detalle, unión de

forjado con muro

de fachada.
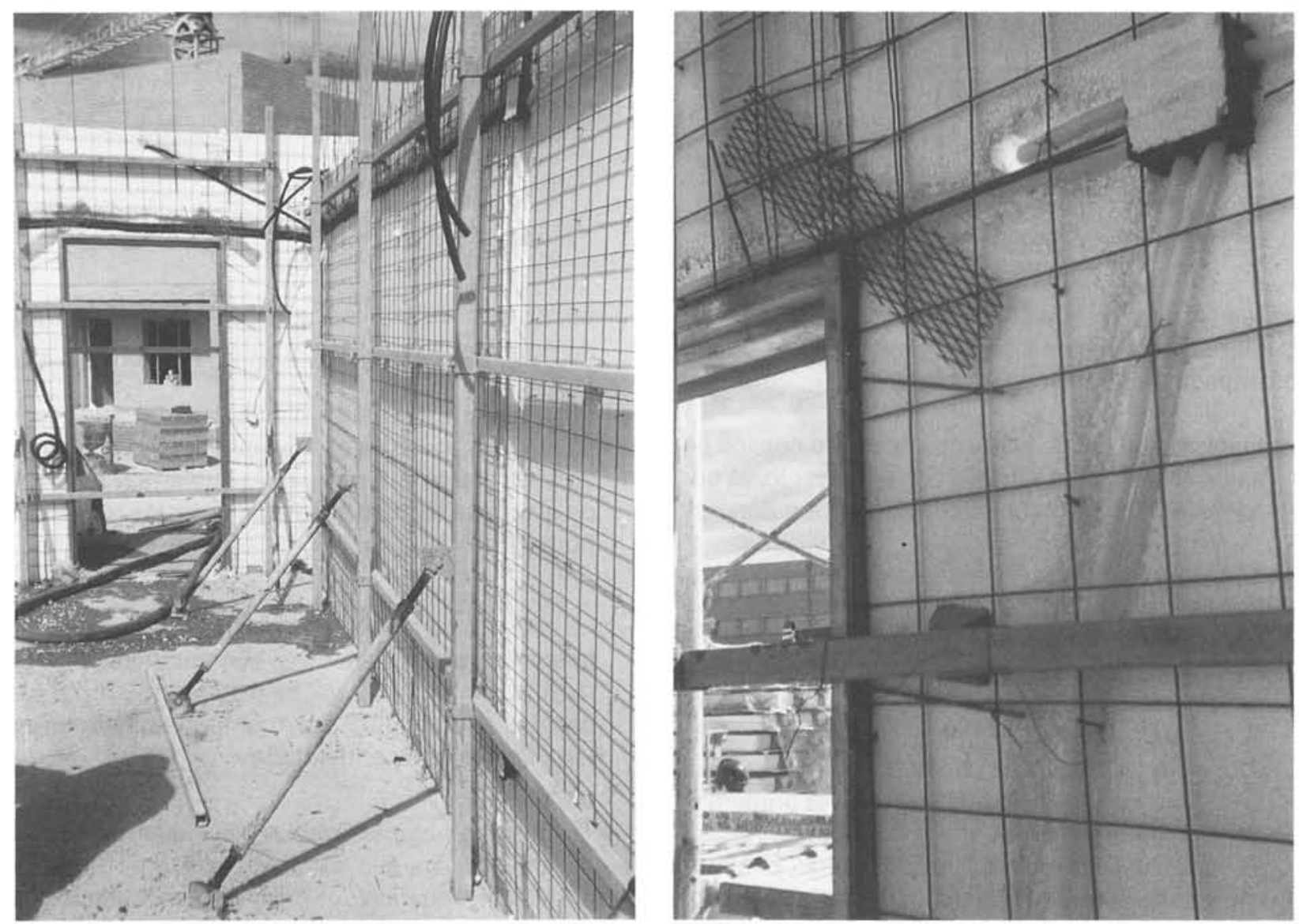

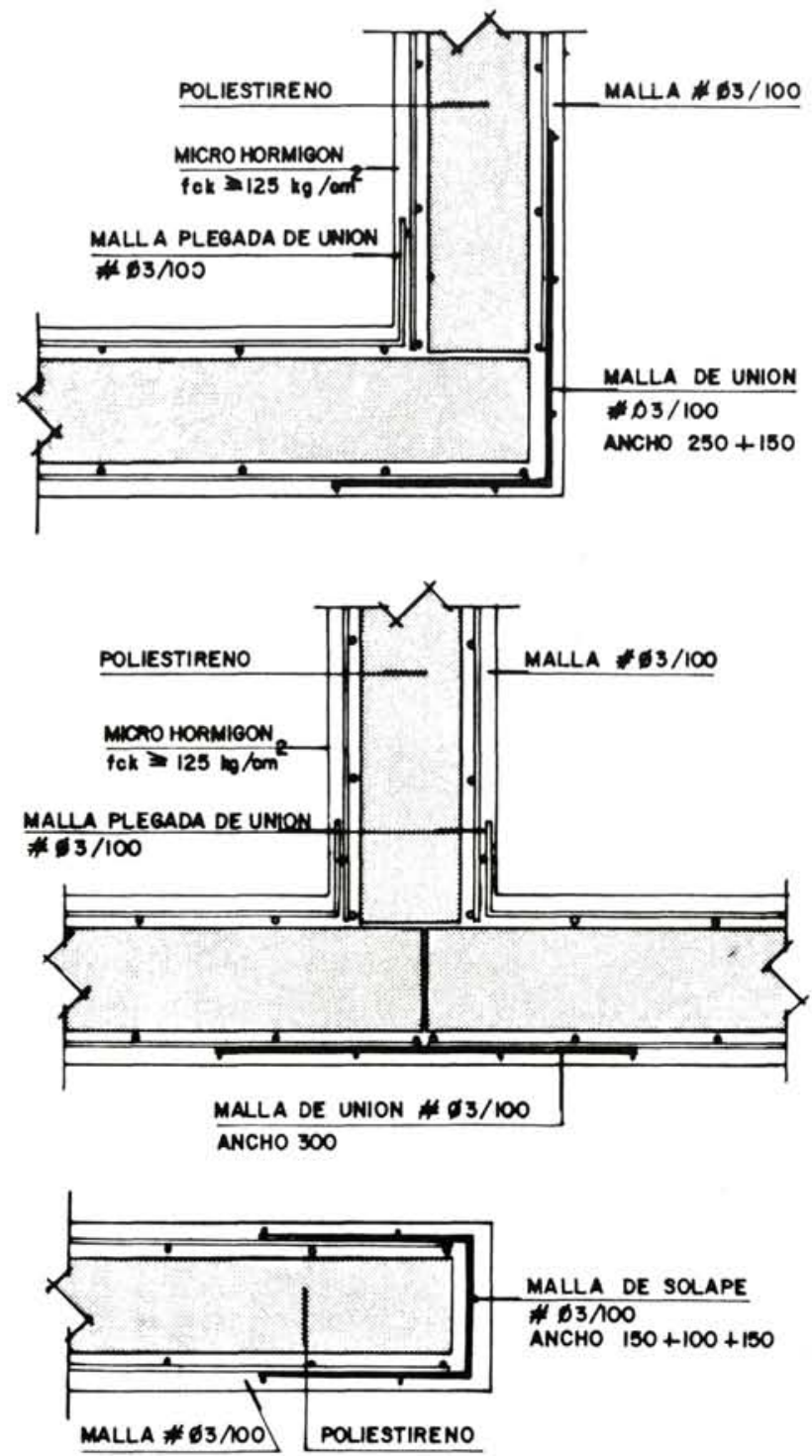

Así las cosas, y siendo éste el primer proyecto en que se utilizaba este sistema, se realizó una revisión de ciertos aspectos del proyecto original:

- El forjado de planta baja y su encuentro con los paneles se realizó de acuerdo con el proyecto, ya que aseguraba la correcta colocación de los paneles.

- En planta primera y cubierta se decidió utilizar un tipo de forjado desarrollado por la empresa constructora para completar el sistema. El forjado Cádiz (que asi se llama), está compuesto por un tablero de cartón-yeso al que van pegados unos bloques de poliestireno expandido que actúan de encofrado para la realización de unos nervios de hormigón. El forjado se realiza en dos fases: en la primera se colocan sobre una bancada (con acabado fratasa. do y bruñido), los tableros de cartón-yeso, posterior a la colocación del poliestireno se hormigonan los nervios a la mitad de su espesor $y$, transcurridas 24 horas, mediante una grúa se elevan y colocan en

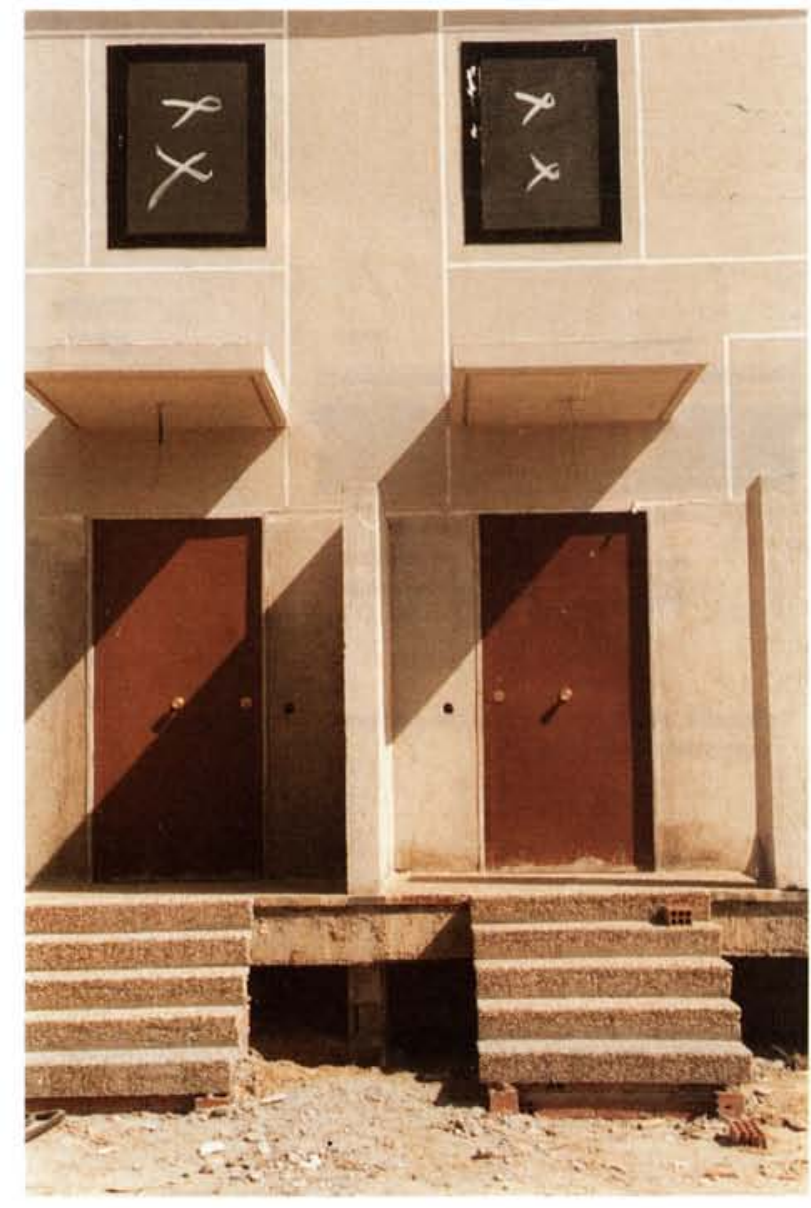

su posición definitiva donde se termina el proceso de hormigonado.

- En la cubierta se sustituyó el tablero de cartón-yeso por otro de poliestireno, asegurando de esta forma un aislamiento suficiente en la cubierta, y rompien. do el puente térmico ocasionado por los nervios de hormigón.

- La losa y vigas de cubierta no se realizaron con los mismos paneles de muros; aunque el cálculo garantizaba su resistencia, se decidió no utilizar los paneles en elementos cuyo comportamiento no es. taba del todo experimentado.

- También se incorporó un sistema industrializado en los baños; para ello se puso el sistema AURREN consistente en un bloque formado por la bañera, el lavabo y el bidé; el inodoro sigue siendo un apara. to convencional. 


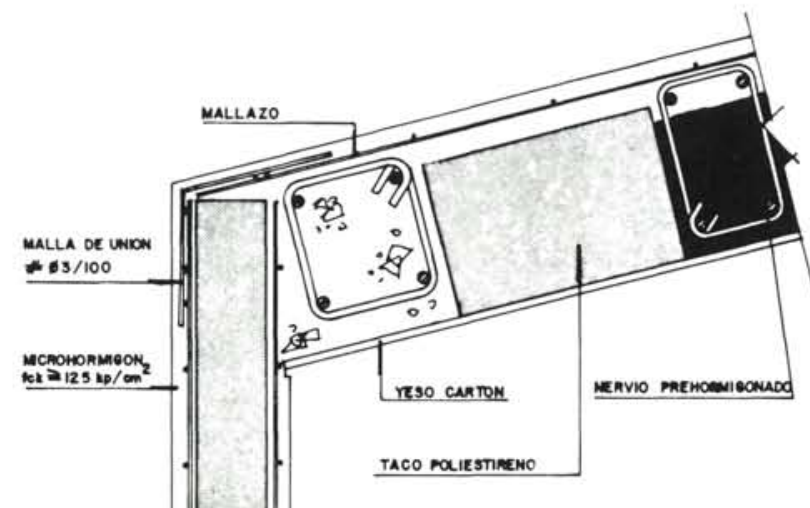

Detalle de forjado

en alero.

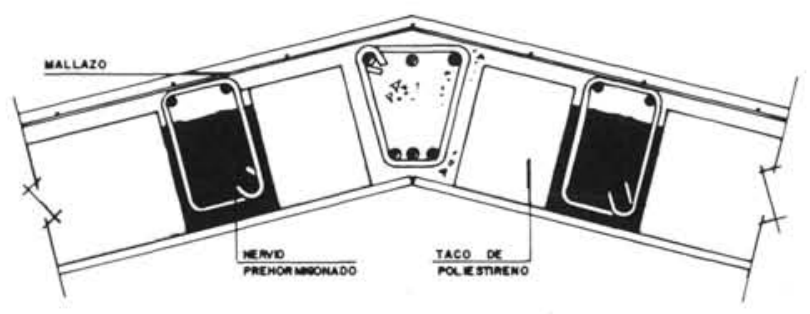

Detalle de forjado

en cumbrera.

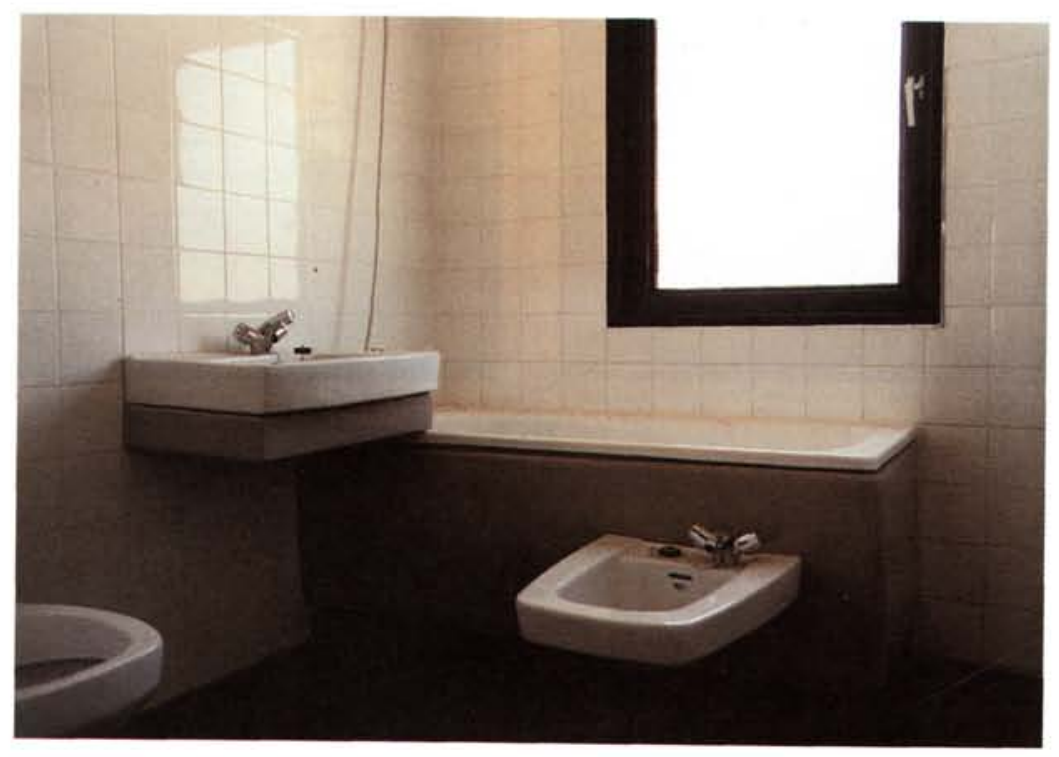

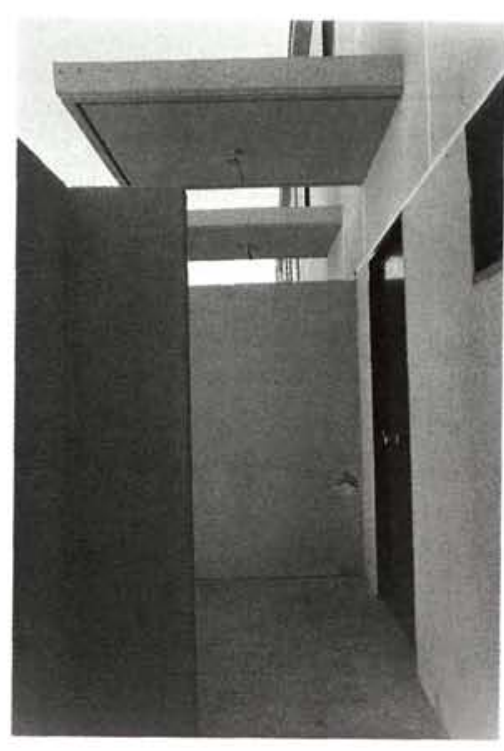

(c) Consejo Superior de Investigaciones Científicas Licencia Creative Commons 3.0 España (by-nc)

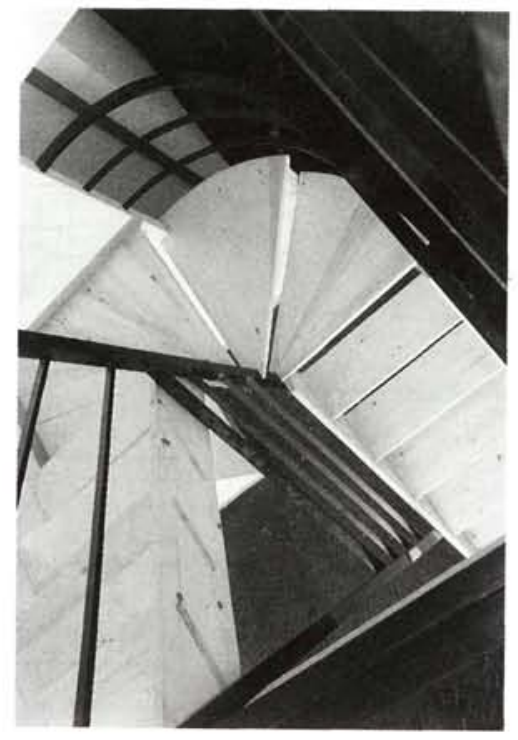

http://informesdelaconstruccion.revistas.csic.es 

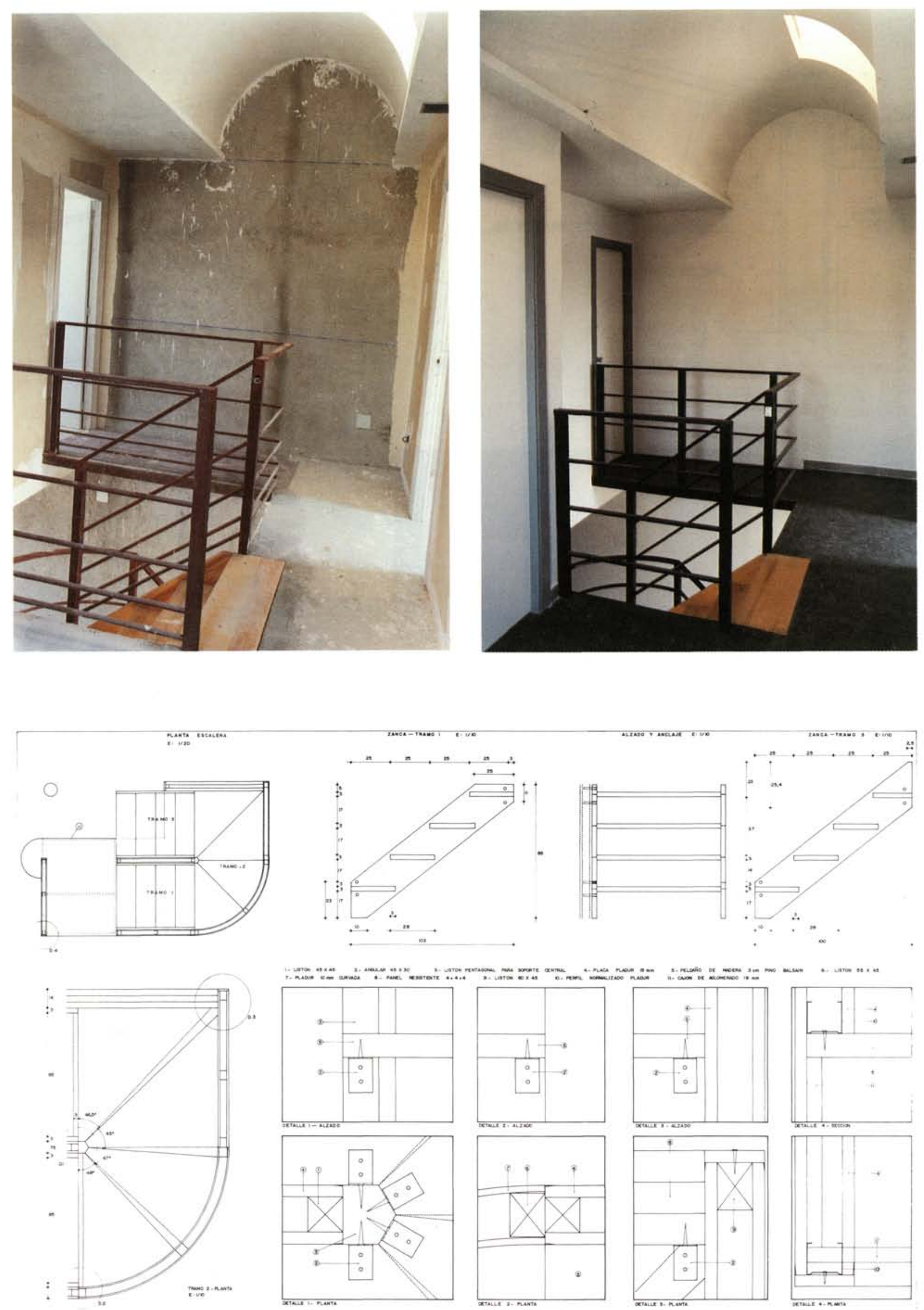


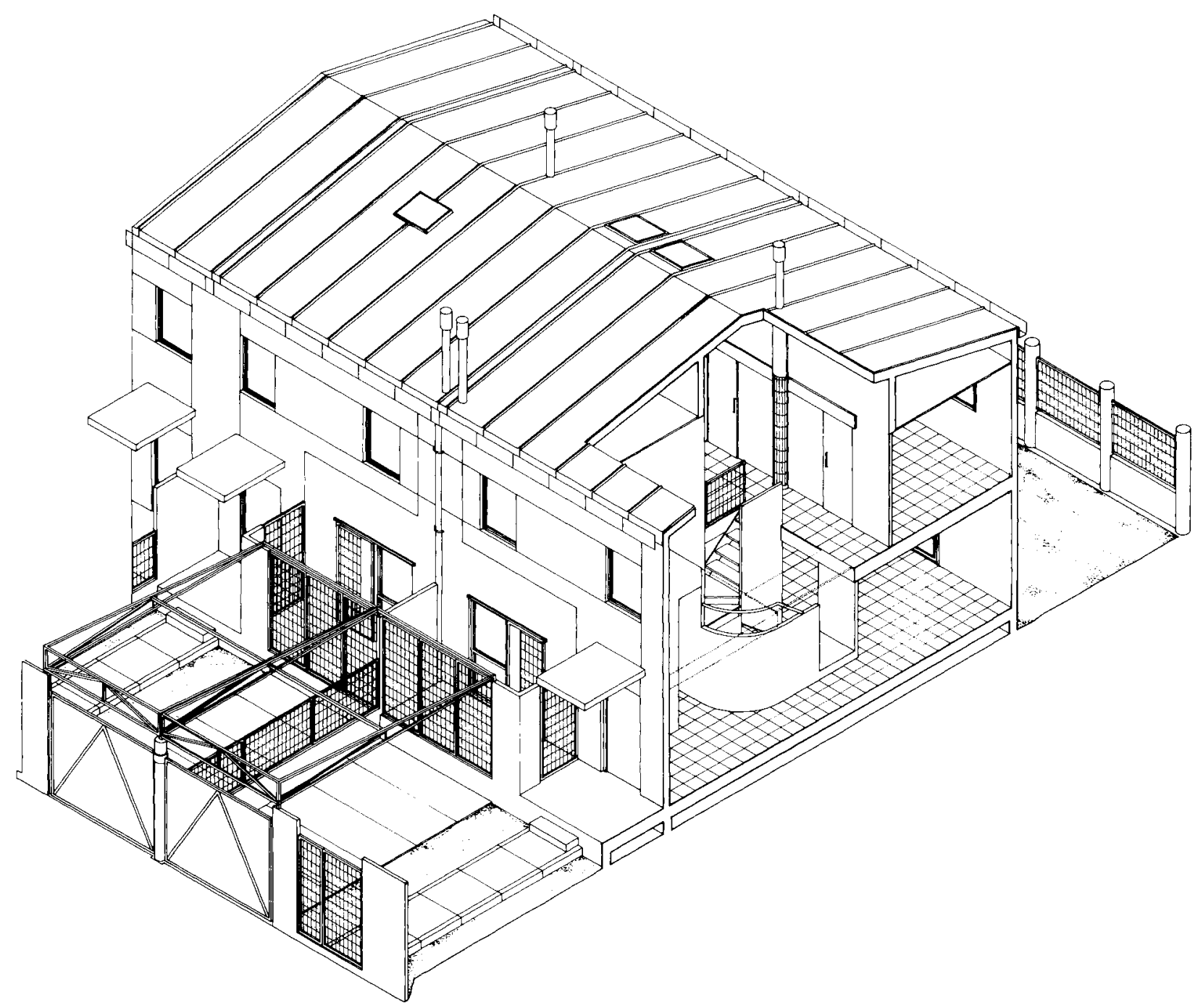

Previamente al inicio de la obra y de cara a conseguir en ésta los rendimientos óptimos, se estudiaron los diseños que permitieran una correcta puesta en obra de los diversos elementos. Así se realizaron de una sola pieza los precercos de la carpintería exterior con chapa de acero galvanizado, cumpliendo, de manera satisfactoria, las funciones de maestra para el proyectado de microhormigón y dando un correcto acabado a los recercados.

Las divisiones interiores se realizaron con tabiques de cartón-yeso y se recuperó el espacio central previsto mediante una bóveda de escayola.

Dado el buen acabado de los paneles, textura y planeidad se decidió eliminar el enlucido interior sobre éstos.

La escalera, en principio un elemento encerrado en sí mismo, se abrió al volumen general de la vivienda; una pequeña estructura metálica y un tabique curvo de cartón-yeso la sujetan, siendo su construcción casi de "bricolage"; los elementos de madera vienen montados del taller y su fijación a la estructura es tarea fácil.

En la actualidad la obra se encuentra todavía en fase de ejecución; el interior de las viviendas se encuentra prácticamente finalizado, pero apenas se han realizado trabajos en la urbanización del conjunto.

De todas maneras, y para finalizar, conviene reseñar que el proyecto se realizó con una gran cantidad de datos experimentales, sin embargo durante la ejecución de la obra se contó, por parte de la empresa constructora, con una gran cantidad de datos basados en obras anteriores, así como diversos resultados de ensayos que hacian desaconsejable su uso en determinados elementos. 